\title{
Interação entre Didática e Teoria Histórico-Cultural
}

Marta Sueli de Faria Sforni'

'Universidade Estadual de Maringá (UEM), Maringá/PR - Brasil

RESUMO - Interação entre Didática e Teoria Histórico-Cultural. O papel nuclear da didática é oferecer conhecimentos que instrumentalizem os professores para a realização da atividade de ensino de conteúdos escolares. Com a finalidade de colaborar para a produção desses conhecimentos, apontamos, neste texto, algumas contribuições que a interação entre os estudos da Didática e da Teoria Histórico-Cultural pode oferecer aos professores. Apresentamos alguns princípios didáticos e ações docentes que, tendo sido objetos de investigação em experimentos didáticos, mostraram-se favoráveis à promoção da aprendizagem conceitual dos estudantes na perspectiva de formação do pensamento teórico.

Palavras-chave: Didática. Teoria Histórico-Cultural. Aprendizagem Conceitual.

ABSTRACT - Interaction Between Didactics and Historic-Cultural Theory. Didactics most relevant role is to provide knowledge that instrumentalizes teachers to implement the activities of teaching school subjects. Current contributions towards the interaction between Didactics and the Historic-Cultural Theory offered to teachers for the production of these types of knowledge are highlighted in this paper. Some didactic principles and teachers' activities are described. Since they have been the object of investigation in didactic experiments, they proved favorable towards the promotion of students' conceptual learning within the perspective of the formation of theoretical thought.

Keywords: Didactics. Historic-Cultural Theory. Conceptual Learning.

Educação \& Realidade, Porto Alegre, v. 40, n. 2, p. 375-397, abr./jun. 2015. 
Interação entre Didática e Teoria Histórico-Cultural

\section{Introdução}

O interesse em tornar a escola um espaço significativo para o desenvolvimento dos sujeitos que a frequentam tem acompanhado nossa trajetória profissional. Os modos de ensinar e aprender foram se constituindo em objetos de nossa atenção, seja na pesquisa seja na prática cotidiana. Nesse percurso, uma afirmação de Vigotski ${ }^{1}$ tem sido extremamente provocativa e desencadeadora de nossas reflexões: “[...] uma correta organização da aprendizagem da criança conduz ao desenvolvimento mental” (Vygostky, 1998, p. 115).

Essa afirmação suscita, quase automaticamente, a pergunta: o que seria uma correta organização da aprendizagem? Sem ter a Didática como foco, Vigotski tangencia um aspecto nuclear desse campo do conhecimento, a organização do ensino. Induz-nos, assim, a entender que a interação entre Teoria Histórico-Cultural e Didática pode ser um caminho promissor para o encaminhamento da prática pedagógica. Nesse sentido, temos procurado investigar, compreender e produzir conhecimentos sobre a organização do ensino.

Nesse percurso de investigação, com o apoio do Grupo de Pesquisa Ensino Aprendizagem e Conteúdo Escolar, pudemos chegar a uma espécie de síntese de princípios didáticos e ações docentes que se mostram favoráveis à aprendizagem. É essa síntese que apresentamos neste artigo.

\section{Unidade entre Função da Escola e Encaminhamentos Didáticos}

Nosso pressuposto é o de que a educação, em sentido amplo, é o processo de humanização caracterizado pela apropriação dos bens culturais produzidos pela humanidade no decorrer da história. Parte dessa apropriação é direta: ocorre por meio da participação dos sujeitos na cultura. Outra, porém, não pode ser captada diretamente pelos sujeitos em sua interação com o mundo; trata-se do conhecimento teórico. Propiciar o acesso a esse bem cultural específico, que não está garantido aos sujeitos por outras práticas culturais, que não se adquire por meio da vivencia e da empiria, é o papel que cabe às instituições de ensino. É por essa especificidade da instituição escolar que se valorizam os conhecimentos sistematizados pelas diferentes ciências - os conhecimentos teóricos - como conteúdos centrais da atividade pedagógica.

Com a perspectiva do desenvolvimento humano, juntamente com a valorização do conteúdo escolar, surge um desafio: criar modos de tornar esses conhecimentos acessíveis a todos, já que nem toda forma de transmissão de conhecimentos científicos caminha nessa direção. Como bem demonstra Davidov² (1988), a escolarização contribui para a humanização dos sujeitos quando propicia o desenvolvimento de um tipo de pensamento que, sob a base dos conceitos científicos, 
favorece uma nova relação com os objetos e fenômenos. Nesse tipo de pensamento, denominado por Davidov (1982) de pensamento teórico, o conceito científico não seria um simples meio de descrição e classificação do mundo objetivo.

O conceito é tratado aqui como forma da atividade mental mediante a qual se reproduz o objeto idealizado e o sistema de suas conexões, que refletem em sua unidade a generalidade e a essência do movimento do objeto material. O conceito aparece tanto como forma de reflexo do objeto material, como meio de sua reprodução mental, de sua estrutura, ou seja, como singular operação mental (Davydov, 1982, p. 300, destaques do autor).

Para levar à formação do pensamento teórico, é preciso que o ensino de conceitos científicos esteja assentado em procedimentos didáticos voltados para a apropriação do conceito como atividade mental, o que em muito se diferencia do modelo de ensino conceitual próprio da tradição escolar e materializado em livros didáticos e apostilas. Organizar o ensino nessa perspectiva é, portanto, um grande desafio já que implica trilhar caminhos ainda pouco conhecidos.

Entendemos que é fundamental enfrentar esse desafio e realizar pesquisas sobre a organização didática do ensino, produzindo conhecimentos para apoio ao trabalho docente.

Na antiga URSS, com base nas produções de Vigotski, segundo Bogoyavlensky e Menchinskaya (1977), promoveu-se um trabalho conjunto entre a Psicologia e a Didática com a finalidade de dinamizar a aprendizagem de conteúdos curriculares.

\begin{abstract}
A colaboração de psicólogos acadêmicos, por um lado, e de quantos se interessavam pela metodologia e a didática, por outro, facilitou o debate e a escolha dos projetos de investigação mais importantes para a escola (Bogoyavlensky; Menchinskaya, 1977, p. 156).
\end{abstract}

Todavia, em terras brasileiras, a Teoria Histórico-Cultural não desencadeou o mesmo processo.

Entre 1980 e 1990, quando essa teoria se tornou conhecida no Brasil, a Didática passava por um momento de autorreflexão e de recuo no trato das questões do ensino. Como denunciam vários pesquisadores (André, 2008; Amaral, 2004; Libâneo, 2008; Marcondes; Leite; Leite, 2011; Oliveira, 2011; Pimenta, 2008; Sforni, 2008), inicialmente, no campo da Didática, evitou-se o tecnicismo (década de 1980); posteriormente, adotaram-se perspectivas de formação advindas das políticas neoliberais (década de 1990 e início deste século), dentre as quais se destacam as discussões sobre sua própria identidade, os estudos de novos temas típicos da pós-modernidade e as pesquisas sobre formação de professores com foco nas representações, nos saberes, nas aprendizagens docentes.

Educação \& Realidade, Porto Alegre, v. 40, n. 2, p. 375-397, abr./jun. 2015. 
Interação entre Didática e Teoria Histórico-Cultural

Em suma, esse campo não tem se destacado pelas investigações sobre o caráter didático do ensino. Na produção acadêmica brasileira observa-se uma lacuna entre as teorias que versam sobre a aprendizagem e aquelas que, por princípio, deveriam se ocupar da organização didática da atividade de ensino. Assim, considerando que a função principal da escola é a socialização do conhecimento produzido historicamente e consolidado nas diversas áreas do conhecimento, entendemos que o domínio desses conteúdos e dos meios de favorecer sua apropriação pelos estudantes são conhecimentos necessários ao professor. Segundo Moraes e Torriglia:

[...] é na relação entre o campo disciplinar e o campo da Didática que se constrói o ser e se produz o conhecimento docente. Ou seja, a apropriação do conhecimento científico - do conteúdo das disciplinas que compõem o campo disciplinar, das formas de sua produção e sua socialização - deve articular-se aos modos de sua transmissão (Moraes; Torriglia, 2003, p. 50).

Reconhecer que a disciplina de Didática é responsável por oferecer conhecimentos acerca de modos de transmitir os conteúdos curriculares não significa reduzi-la à dimensão técnica e sim que os modos de transmissão do conhecimento são o núcleo em torno do qual giram os conteúdos teóricos da formação docente.

Evitar o tecnicismo não significa negar a necessidade de conhecimentos acerca da dimensão técnica e operacional do trabalho docente. Afinal, o problema não é a técnica em si, mas o uso da técnica da qual se desconhecem a origem, a razão e os resultados. O conhecimento da técnica em seus aspectos apenas operacionais, de fato, enrijece o trabalho e aliena o professor, torna-o mero executor de procedimentos cujos significados lhe são alheios. Assim, para que a prática do professor não se caracterize por essa alienação, a saída não está na desvalorização de discussões sobre metodologias e técnicas de ensino, mas no oferecimento de conhecimentos teóricos sobre elas. Para que a ação do professor não seja uma repetição irrefletida de procedimentos presentes em livros didáticos ou em modelos de aula disponíveis na mídia, o conhecimento acerca das bases teóricas nas quais as metodologias e técnicas estão assentadas faz-se necessário. Essa é uma condição, embora não a única, para que ele seja sujeito de sua própria ação.

A reflexão sobre as ações docentes e discentes, orientada pelo fim que se deseja atingir, é inerente ao processo de planejamento da atividade de ensino. Ou seja, tão importante quanto à clareza sobre o que se deseja produzir (o tipo de aprendizagem almejada) é o domínio dos meios que tornam possível essa produção. Não basta ao professor concordar com pressupostos vigotskianos de que o papel da escola é a humanização dos sujeitos, de que o conteúdo escolar é importante para essa finalidade ou de que é sua função mediar esses conhecimentos; é 
necessário também que ele domine os instrumentos necessários para fazê-lo.

As discussões acerca da função da escola e a definição dos encaminhamentos didáticos formam uma unidade. Os cursos de formação, ao considerarem essa unidade, podem oferecer aos professores conhecimentos que os auxiliem a levar em conta o objeto do conhecimento e a atividade necessária ao estudante para que este se aproprie desse saber, enfim, que os auxiliem a compreender e organizar o ensino. Trata-se de um conhecimento acerca do objeto de ensino (conteúdo), sobre o sujeito da aprendizagem e, principalmente, sobre as relações entre os dois em situação de ensino.

É fato que as teorias não oferecem respostas definitivas e diretas para o enfrentamento de todos os desafios da docência, mas o reconhecimento desse fato não as torna dispensáveis. Os conhecimentos sobre a didática e os processos de ensino e aprendizagem constituem instrumentos simbólicos valiosos para que o professor analise e redefina sua prática. Por meio desses conhecimentos, ele adquire a flexibilidade necessária para pensar e redefinir os princípios e ações conforme as situações particulares e singulares encontradas nas condições concretas de cada sala de aula. Pode, portanto, analisar o concreto pela mediação dos conhecimentos teóricos de sua área de atuação, adquirindo, assim, domínio sobre sua própria atividade.

\section{Experimentos Didáticos como Metodologia de Pesquisa}

Com foco específico no papel da atividade interpsíquica para a promoção do desenvolvimento humano, os autores da Teoria Histórico-Cultural deixam pistas para pensarmos a organização de um ensino com a mesma finalidade. Assim, embora essa teoria não tenha sido produzida com a finalidade pedagógica de orientar a ação docente, podemos identificar nela princípios educativos. Nascimento (2010), compartilhando desse mesmo entendimento, destaca alguns desses princípios:

A despeito de ser uma teoria da ciência psicológica, podemos identificar, na teoria histórico-cultural, alguns princípios educativos gerais, tais quais: a) a concepção de homem como um sujeito histórico; b) a compreensão da formação social da consciência; c) a definição da educação como um processo de apropriação da experiência social da humanidade; d) a defesa do desenvolvimento do psiquismo como resultado da atividade prática humana, mediada pelos signos e instrumentos; e) o entendimento de que as funções psíquicas superiores são primeiro compartilhadas entre os sujeitos (interpsíquicas) e posteriormente internalizadas (intrapsíquicas); f) a defesa de que a apropriação dos conhecimentos é sempre uma atividade mediada por outras pessoas (colaboração dos mais experimentes) (Nascimento, 2010, p. 102).

Educação \& Realidade, Porto Alegre, v. 40, n. 2, p. 375-397, abr./jun. 2015. 379 
Interação entre Didática e Teoria Histórico-Cultural

A autora considera que tais princípios têm um potencial prático para a organização do ensino, mas, por si mesmos, não se constituem como princípios didáticos.

De fato, nas discussões sobre as contribuições da Teoria Histórico-Cultural para o ensino, a tônica tem sido a repetição desses princípios educacionais amplos, sendo raro o diálogo com a Didática (Sforni, 2013). Assim, fica ao encargo do professor fazer a transposição, nada simples, desses princípios para a prática pedagógica. Talvez seja por isso que, embora essa teoria conste como pressuposto teórico nos PPPs (projetos político-pedagógicos) de algumas escolas, não se observa uma modificação significativa na organização cotidiana do seu ensino, especialmente no que se refere à estruturação do conteúdo, às metodologias de ensino e à avaliação da aprendizagem.

Concordamos com Nascimento (2010) quando afirma que, para elaborar um modo geral de ação educativa, “[...] precisamos realizar um movimento tanto de aprofundamento destes conceitos presentes na teoria histórico-cultural, quanto de novas elaborações teóricas que partam deles" (Nascimento, 2010, p. 103). Essas novas elaborações teóricas, em nosso entendimento, não podem prescindir do diálogo com a própria prática pedagógica. Por meio da análise de dados de campo, é possível elucidar, referendar, redimensionar e/ou reestruturar esses conceitos tendo em vista a aprendizagem de um tipo específico de conhecimento, o teórico, em um contexto particular, a sala de aula.

Nesse sentido, experimentar modos de organização do ensino e acompanhar o seu impacto na aprendizagem dos estudantes tem sido nosso caminho para atingir esse fim. Em nossos projetos de pesquisa, utilizamos uma metodologia inspirada nos princípios do método genético experimental de Vigotski (1993) para o estudo da elaboração de conceitos e no experimento formativo, elaborado por Zankov e utilizado por Davydov (1988).

Segundo Zankov:

A aplicação do experimento na investigação científica permite estudar as relações de determinadas facetas do processo e achar as causas que condicionam a necessidade de que apareça o fenômeno dado. Desse modo, o experimento permite evidenciar as leis da esfera da realidade objeto de estudo (Zankov apud Aquino, 2013, p. 240) ${ }^{3}$.

Considerando que nossas pesquisas não se situam no campo da Psicologia e sim no da Educação, já que são movidas pela necessidade de investigar procedimentos didáticos que favoreçam a aprendizagem e o desenvolvimento dos estudantes, utilizamos o procedimento metodológico denominado de experimento didático ${ }^{4}$. Nesse caso, o pesquisador planeja atividades de ensino especialmente para fins da pesquisa, cuja intenção é intervir para colocar em movimento os processos que 
visa investigar. Para isso, atua como professor ou em conjunto com o professor da sala de aula.

\begin{abstract}
Para o método do experimento formativo é característico a intervenção ativa do investigador nos processos psíquicos que ele estuda. [...] Para nós, se pode chamar ao experimento formativo experimento genético modelador, o que traduz a unidade entre a investigação do desenvolvimento psíquico das crianças e sua educação e ensino (Davidov, 1988, p. 196, grifos do autor).
\end{abstract}

As fontes de pesquisa são aulas videogravadas, materiais escritos e outros tipos de material produzidos pelo professor/pesquisador e pelos estudantes durante a intervenção. Na análise, a atenção do pesquisador volta-se tanto para os dados do ensino quanto para os da aprendizagem, já que a intenção é identificar o efeito da interação entre esses dois processos.

Experimentos didáticos realizados em diferentes áreas do currículo escolar da Educação Básica resultaram na identificação de alguns princípios didáticos e ações docentes que se mostraram favoráveis à aprendizagem. Esses resultados, portanto, podem sinalizar para os professores algumas possibilidades de organização do ensino.

Cada um dos experimentos ${ }^{5}$ do grupo teve uma especificidade, seja pelo nível de ensino e pela área do conhecimento em que foi realizado, seja pela própria singularidade dos proponentes e executores. Embora isso tenha acarretado modos diferenciados de ação e focos específicos na análise dos dados, algumas ações se repetiram, evidenciando seu valor pedagógico em todos os experimentos. São essas ações e os correspondentes princípios que as orientaram que procuramos relatar neste artigo.

\title{
Princípios Didáticos e Ações Docentes Favoráveis à Aprendizagem
}

Ao defender um ensino voltado para o desenvolvimento do pensamento teórico pelos estudantes, nosso objetivo não é criar uma Didática com base na Teoria Histórico-Cultural e sim identificar alguns princípios que possam orientar os professores nos momentos de planejamento, execução e avaliação do ensino. Os estudos de Moura (1996; Moura, 2001; Moura, 2010), Núñez (2009) e, mais recentemente, de Nascimento (2010) também apontam princípios ou ações didáticas com base nessa perspectiva teórica e, assim, foram tomados como referência em nosso trabalho.

Observamos uma estreita sintonia entre as produções desses autores, especialmente quanto às orientações didáticas que apresentam, ou seja, notamos que seus textos expressam os resultados de um ensino pautado na Teoria Histórico-Cultural e na Teoria da Atividade. Por isso,

Educação \& Realidade, Porto Alegre, v. 40, n. 2, p. 375-397, abr./jun. 2015. 381 
Interação entre Didática e Teoria Histórico-Cultural

mais do que simplesmente referendá-los, optamos por destacar os princípios por eles apresentados e que foram intencionalmente colocados em movimento nos experimentos realizados por nosso grupo. Assim, a síntese que ora apresentamos teve por base: a) as obras de autores da Teoria Histórico-Cultural (Vigotski, Luria, Leontiev, Elkonin, Galperin e Davidov); b) as obras de autores brasileiros que, apoiados nessa teoria, têm refletido a respeito da Didática (Moura, Núñez e Nascimento) e c) os dados coletados durante experimentos didáticos realizados em sala de aula por nosso grupo de pesquisa. Ressaltamos que os dados das pesquisas de campo realizadas por esse grupo foram decisivos na definição dos princípios que deveríamos abordar neste artigo.

Destacamos cinco princípios orientadores da ação docente:

1. Princípio do ensino que desenvolve

2. Principio do caráter ativo da aprendizagem

3. Princípio do caráter consciente

4. Princípio da unidade entre o plano material (ou materializado) e o verbal

5. Principio da ação mediada pelo conceito

Destacamos também as ações docentes que materializam cada um desses princípios na atividade de ensino.

\section{Princípio do Ensino que Desenvolve}

Orientar-se pelo princípio do ensino desenvolvimental ${ }^{6}$ implica considerar que, ao planejar, executar e avaliar o ensino, o norte deve ser o próximo desenvolvimento dos estudantes.

Analisemos o argumento apresentado por Davidov e Markova:

Se a assimilação é a reprodução pela criança da experiência socialmente elaborada e o ensino é a forma de organização desta assimilação, aceita nas condições históricas concretas na sociedade dada, o desenvolvimento se caracteriza, principalmente, pelos avanços qualitativos no nível e na forma das capacidades, nos tipos de atividade etc. dos quais se apropria o indivíduo (Davídov; Márkova, 1987, p. 322).

A experiência socialmente elaborada, sistematizada em forma de linguagem, compõe os conteúdos das diferentes áreas do conhecimento, os quais, quando apropriados pela criança, promovem seu desenvolvimento. Assume-se, portanto, que essa experiência é o conteúdo central do ensino com a perspectiva desenvolvimental.

Ao caracterizar o desenvolvimento por avanços qualitativos no nível e na forma das capacidades e nos tipos de atividades do sujeito, os autores deixam implícito o processo de passagem de um nível de desenvolvimento a outro. Torna-se, então, uma exigência conhecer o nível de desenvolvimento presente dos estudantes para planejar ações 
adequadas à passagem para o próximo nível. Embora esse nível inicial possa ser identificado por meio de avaliação formal do desempenho dos estudantes, conta-se também com avaliações informais resultantes da observação, da análise de atividades dos estudantes, dos diálogos com a turma, dentre outros procedimentos.

Segundo os professores, a maior dificuldade que eles enfrentam ao atuar sobre o desenvolvimento dos estudantes nas situações de ensino específicas do contexto escolar relaciona-se ao fato de a sala de aula ser um espaço coletivo, não individual, de aprendizagem. Assim, ao mesmo tempo em que o professor tem a clareza de que é necessário atuar sobre a Zona de Desenvolvimento Próximo (ZDP), enfrenta o desafio de fazê-lo em uma sala de aula composta por alunos com diferentes níveis de desenvolvimento. Isso parece inviabilizar a efetivação de uma prática comprometida com o desenvolvimento, nos termos da Teoria Histórico-Cultural.

Em nossas pesquisas, temos procurado adequar esse princípio geral ao contexto particular em que ocorrem as situações de ensino, diferenciando atividades coletivas e atendimentos individualizados. Embora na sala de aula prevaleçam atividades coletivas, é possível contemplar as duas situações: o atendimento individualizado pode acontecer em alguns momentos da aula, mas, sobretudo, em horários e espaços próprios para isso.

No caso do ensino individualizado, parece não haver dificuldade para a atuação específica sobre a Zona de Desenvolvimento Próximo; no entanto, essa atuação não pode ser descartada nas situações coletivas de ensino. Em nossos experimentos didáticos, procuramos identificar o que poderia ser chamado de Zona de Desenvolvimento Próximo da turma, ou seja, procuramos identificar os conhecimentos e capacidades que são comuns à turma, as aprendizagens que, de modo geral, já estão consolidadas e as que merecem investimento. O desenvolvimento de cada criança ocorre de forma singular, no entanto, há traços comuns entre estudantes de uma mesma sala de aula, seja porque participaram de situações sociais de desenvolvimento semelhantes, seja porque frequentaram a mesma sala de aula, a mesma escola, seja ainda porque participaram ou participam da mesma comunidade. Enfim, os estudantes de uma sala estão envoltos em uma mesma cultura na escola e na comunidade e partilham um histórico semelhante. Essa também é a compreensão de Hedegaard:

Embora cada criança seja única, as crianças obviamente compartilham traços comuns com as outras crianças. Sendo da mesma tradição, as crianças na mesma classe tem um grande volume de conhecimento e habilidades em comum. O ensino pode ser construído com base nesses aspectos comuns, se levar em conta que as crianças variam em sua velocidade e forma de aprendizagem (Hedegaard, 2002, p. 224).

Educação \& Realidade, Porto Alegre, v. 40, n. 2, p. 375-397, abr./jun. 2015. 383 
Interação entre Didática e Teoria Histórico-Cultural

Atuando com base nesses aspectos, é possível organizar situações de ensino em sala de aula, atendendo a todos e, ao mesmo tempo, a cada um dos estudantes. Um levantamento acerca dos conhecimentos e das habilidades de cada estudante, com a finalidade de conhecer o que é comum à turma e avaliar seu desenvolvimento atual e potencial, oferece ao professor a possibilidade de atuar coletivamente, sem que isso constitua uma negação da especificidade do desenvolvimento de cada aluno.

Esse levantamento inicial serve como referência para o professor selecionar os conteúdos e definir o modo de abordá-los. Assim, além de integrar o planejamento do ensino, constitui-se como parâmetro para acompanhar o processo, ou seja, oferece elementos para que o professor realize a avaliação contínua do processo. Comparando o ponto de partida e a expectativa de aprendizagem, este tem condições de, quando necessário, redirecionar as ações de ensino ainda durante o percurso. Os dados iniciais também são uma referência para avaliação final do processo, pois oferecem parâmetros para a verificação do que se modificou nos conhecimentos e habilidades dos estudantes, após uma aula, unidade de ensino ou curso.

Enfim, o levantamento inicial, aliado à clareza do professor sobre o desenvolvimento esperado do aluno, serve como parâmetro para as avaliações inicial, contínua e final do processo de aprendizagem dos estudantes, bem como para a da eficácia do caminho percorrido pelo professor. Isso significa que a identificação da Zona de Desenvolvimento Próximo não é apenas um procedimento que precede a aula, mas também um norte para as ações do professor ao longo da intervenção pedagógica.

A perspectiva do desenvolvimento dos estudantes precisa ser materializada na forma de abordagem dos conteúdos e nas ações a serem realizadas pelos alunos, pois o pensamento teórico vincula-se ao desenvolvimento das Funções Psíquicas Superiores, que se desenvolvem com a própria atividade do sujeito. Ou seja, a atenção, a percepção, a memória, o raciocínio, a imaginação, o sentimento desenvolvem-se à medida que são ativados. Tais atividades, no entanto, não se reduzem a exercícios para o desenvolvimento dessas funções: devem ser realizadas com os conteúdos curriculares, colocando, de maneira integrada, essas funções em movimento. Cada atividade escolhida ou elaborada pelo professor deve ser analisada em seu potencial para a mobilização das funções psíquicas. Com base nessa análise, algumas atividades podem ser consideradas mais adequadas ou menos adequadas para a sala de aula. Tarefas como siga o modelo, defina, exemplifique, liste, dentre outras do gênero tendem a exigir dos estudantes pouca atividade psíquica, diferenciando-se, assim, de outras tarefas, como explique, analise, justifique, demonstre, argumente. Enfim, tarefas que exigem o uso do conceito para serem adequadamente respondidas tendem a ativar a

384 Educação \& Realidade, Porto Alegre, v. 40, n. 2, p. 375-397, abr./jun. 2015. 
atenção, a memória, o raciocínio, ou seja, um conjunto de funções que, colocadas em movimento, são desenvolvidas.

É fato que a atividade mental do estudante é algo subjetivo e não pode ser captada diretamente pelo professor; no entanto, resulta em manifestações externas, como os gestos e a linguagem oral, que podem sinalizar a atividade mental que o aluno está realizando com o conteúdo. Mais do que verificar se a resposta do aluno está certa ou errada, é preciso observar se, em sua explicitação verbal durante a realização das atividades, ele está caminhando em direção à abstração e à generalização do conteúdo ou se está preso à situação particular da atividade realizada. Nesse sentido, tal explicitação verbal pode se apresentar como um diagnóstico da eficácia do ensino sobre a Zona de Desenvolvimento Próximo.

Em síntese, podemos destacar algumas ações docentes motivadas pelo princípio do ensino que desenvolve:

a) avaliação do nível de desenvolvimento atual e previsão do nível de desenvolvimento esperado;

b) uso de atividades com os conceitos que mobilizam as Funções Psíquicas Superiores;

c) criação de situações em que os estudantes expressem verbalmente o que e como estão pensando (como estão atuando mentalmente com os conceitos).

\section{Princípio do Caráter Ativo da Aprendizagem}

A defesa de que o objetivo principal da escola é a transmissão-assimilação do conhecimento sistematizado não pode ser confundida com a aceitação de um modelo linear e mecânico de transmitir e assimilar conhecimentos. À valorização do conteúdo deve ser aliado o principio do caráter ativo da aprendizagem para que não sejam, em nome da teoria, defendidas metodologias tradicionais de ensino que foram criticadas pelo próprio Vigotski:

A experiência pedagógica nos ensina não menos do que a investigação teórica que o ensino direto de conceitos é impossível e, na verdade pedagogicamente infrutífero. $\mathrm{O}$ professor que tenta seguir esse caminho geralmente não conseguira mais que uma assimilação irrefletida de palavras, um simples verbalismo, que simula e imita os conceitos correspondentes na criança, mas na verdade esconde um vácuo. Em tais casos, a criança não adquire conceitos, mas palavras, assimila mais com a memória do que com o pensamento e sente-se impotente diante de qualquer tentativa de empregar com sentido o conhecimento assimilado. Em essência, este procedimento de ensino dos conceitos é o defeito fundamental do método verbal de ensino, puramente escolástico, que todos con- 
Interação entre Didática e Teoria Histórico-Cultural

denam. Este método substitui o domínio dos conhecimentos vivos pela assimilação de esquemas verbais mortos e vazios (Vygotski, 1993, 185).

A aprendizagem dos conceitos científicos é valorizada por essa perspectiva teórica porque possibilita a "[...] transformação qualitativa no desenvolvimento do psiquismo da criança” (Davídov; Márkova, 1987, p. 324). No entanto, essa transformação não ocorre se, no ensino, a linguagem (definição do conceito) for dissociada do pensamento conceitual (processos psíquicos mediados pelo conceito).

Para que haja unidade ente linguagem e pensamento, ou, dito de outra forma, para que de fato se aprendam conceitos e não apenas palavras ou procedimentos vazios de significado, é necessário que o estudante atue mentalmente com o conceito. Nesse sentido, o princípio ativo da aprendizagem implica a participação efetiva do aluno na elaboração da síntese conceitual, na qual estão aliados pensamento e linguagem.

Não estamos, com isso, aderindo à concepção de que o estudante, individualmente, constrói seu próprio conhecimento; nossa perspectiva é a de uma elaboração conjunta entre professores e estudantes, orientada pelo professor.

Esse princípio tem por base a compreensão de que, mediante o ensino, desenvolvem-se, conjuntamente, forma e conteúdo do pensamento. Não se trata de uma acumulação conhecimentos já em sua síntese, em sua definição verbal ou "[...] cobertura verbal", como nomeia Davidov (1987, p. 148), mas sim de uma apropriação do processo lógico-histórico de elaboração do conceito e, ao mesmo tempo, do desenvolvimento conjunto de formas de pensamento mais complexas.

[...] o caráter real dos conhecimentos não consiste nas abstrações verbais, mas sim nos procedimentos de atividade do sujeito cognoscente, para quem a transformação dos objetos, a fixação dos meios de tais transformações constituem um componente tão indispensável dos conhecimentos como sua cobertura verbal (Davídov, 1987 p. 148).

O estabelecimento dessa relação ativa com o conhecimento permite ao aluno compreendê-lo como produção humana em movimento, como resposta às necessidades humanas produzidas ao longo da história, não como verdade atemporal, absoluta e imutável.

No processo de elaboração da síntese pelos estudantes, ações mentais de reflexão e análise são colocadas em movimento e, portanto, desenvolvidas. Nos experimentos realizados por nosso grupo de pesquisa (Rodrigues, 2006; Cavaleiro, 2009; Belieri, 2012; Oliveira, 2013), observamos que, quando os estudantes participam ativamente da elaboração da síntese, eles têm maior facilidade para generalizar o conhecimento aprendido, aplicando o conhecimento abstrato a situações concretas.

386 Educação \& Realidade, Porto Alegre, v. 40, n. 2, p. 375-397, abr./jun. 2015. 
Além disso, a necessidade e o motivo para aprender um determinado conteúdo não existem a priori no aluno, são criados no decorrer da atividade. Portanto, oferecer o conteúdo sem que o aluno esteja envolvido com as problematizações relacionadas a tal conteúdo, sem que esteja inserido na compreensão das razões humanas da elaboração dessa síntese, assemelha-se a oferecer a alguém respostas a perguntas que não $f e z$. A falta de sentido da informação para o sujeito manifesta-se em sua apatia diante dela. É, portanto, necessário criar a necessidade e o motivo no estudante, o que significa inseri-lo no horizonte investigativo que deu origem ao conceito (Davidov, 1988), tendo a síntese como elaboração abstrata do percurso de sua elaboração.

Algumas atividades favorecem a formação de necessidades e motivos para a apropriação do conhecimento pelos alunos. É o caso de jogos; situações problema criadas por meio de narrativas reais ou imaginárias, semelhantes às vividas pelos homens quando elaboram determinados conhecimentos; problemas relacionados a fenômenos cotidianos; filmes; notícias, etc. Tais situações problema desencadeiam nos estudantes ações mentais inerentes ao conceito que é objeto de estudo. Por essa razão, Moura $(1996 ; 2001)$ inclui a criação do problema desencadeador da aprendizagem como um dos elementos fundamentais no planejamento da atividade de ensino e, dependendo da idade e da área de conhecimento, a forma de fazer isso pode ser adequada ou não. Além das situações problema, as tarefas coletivas que exigem discussão e elaboração conceituais em grupo mostram-se favoráveis ao processo ativo do estudante. Dentre essas tarefas, destacamos o estabelecimento de diálogo entre os alunos de um grupo com a finalidade de elaborar a síntese, bem como as situações intergrupos, cuja finalidade é apresentar essas sínteses para os demais (Bernardes, 2012).

Observamos nos experimentos (Rodrigues, 2006; Cavaleiro, 2009; Belieri, 2012; Oliveira, 2013) que esses momentos em grupo, orientados e acompanhados pelo professor, induzem o aluno a ter mais cuidado na explicitação verbal de seu pensamento do que quando seu interlocutor é apenas o professor. Ao se dirigir aos colegas, para ser entendido, ele não pode elaborar e apresentar seus argumentos com meias palavras, como faz com o professor. Explicar algo ou negociar significados com os colegas é diferente de dialogar com o professor e exige do aluno mais clareza na elaboração e na explicitação dos argumentos.

Em síntese, podemos destacar algumas ações docentes motivadas pelo princípio do caráter ativo da aprendizagem:

a) elaboração de situações problema que permitam inserir o estudante no horizonte investigativo que deu origem ao conceito;

b) previsão de momentos em que os alunos dialoguem entre si e elaborem sínteses coletivas, mesmo que sejam provisórias;

c) orientação do processo de elaboração de sínteses conceituais pelos estudantes.

Educação \& Realidade, Porto Alegre, v. 40, n. 2, p. 375-397, abr./jun. 2015. 
Interação entre Didática e Teoria Histórico-Cultural

\title{
Princípio do Caráter Consciente
}

Considerar que o estudante deve ser consciente da aprendizagem parece óbvio; afinal, em princípio, os alunos estão na escola com a consciência de que, nesse local, realizam atividades cuja finalidade é a aprendizagem de conteúdos específicos. No entanto, Leontiev (1983) alerta-nos para o fato de que, muitas vezes, a própria organização da atividade leva o estudante a se afastar daquilo que seria o conteúdo de aprendizagem. Alguns exemplos: para ensinar conceitos históricos, o professor utiliza-se de um filme, um drama ambientado em um determinado momento histórico, mas os alunos ficam atentos ao aspecto romanesco e não ao contexto histórico retratado no filme; o professor recorre a receitas para ensinar unidades de medidas de massa e de volume, mas a atenção dos alunos volta-se mais para a receita em si do que para as unidades de medida; o professor trabalha com um projeto ambiental que integra conhecimentos biológicos e geográficos, mas os alunos prendem-se ao discurso da conscientização e pouco aos conceitos de biologia e geografia.

Situações desse tipo levam os professores a considerar que, se os conteúdos foram ensinados, devem ter sido aprendidos. Quando percebem que isso não aconteceu, não conseguem compreender a razão. Acontece que, nesses casos, mesmo estando contido na atividade, o conteúdo não foi objeto da atividade mental dos estudantes e, portanto, não resultou em aprendizagem.

Segundo Leontiev (1983), o conteúdo pode ter sido percebido pelo aluno, mas não conscientizado, pois o plano da percepção é amplo, ao passo que o da atenção - objeto da consciência - é estreito, tem foco específico. Se, no aluno, não surge uma atividade mental com o conteúdo central de ensino, a tendência é sua atenção deslocar-se para outro conteúdo, normalmente mais estimulante aos sentidos ou mais emocionante, conforme demonstram os exemplos.

Isso evidencia que, se o ensino direto de conceitos é infrutífero, como afirma Vigotski (1993), caso não sejam tomados alguns cuidados, também a criação de situações que contextualizam o conceito pode não ser tão favorável à aprendizagem. No caso de situações problema, se o estudante se mantiver atrelado à especificidade do problema, se considerar um problema prático e não teórico, não conseguirá se apropriar do conhecimento geral que se pretende ensinar por meio da situação particular apresentada. Como afirma Nascimento (2010):

\begin{abstract}
A solução de um problema de aprendizagem constitui-se mais na explicitação de um modo geral de ação por parte do educando e, portanto, na apropriação de um conceito pelo estudante, do que na resolução concreta do problema, ainda que essa resolução sempre se dê. Em outras palavras, a resolução concreta de um problema deve ser considerada como um caso particular da resolução geral
\end{abstract}


do problema, isto é, do modo geral de ação para resolver aqueles tipos de problemas (Nascimento, 2010, p. 115).

O mesmo pode ocorrer com a contextualização de conceitos por meio de projetos interdisciplinares: se a ênfase recair mais no tema do projeto do que nos conceitos científicos presentes, estes podem não ser tão favoráveis à aprendizagem dos conceitos. Se estes não forem o foco da atenção e da atividade mental dos estudantes durante a realização do projeto (Sforni, 2010), por mais rico que seja, ele pode não resultar na aprendizagem esperada.

Durante os experimentos foi possível reconhecer que a transição da situação singular, apresentada como desencadeadora do ensino de conceitos, para a abstração daquilo que é essencial, o que poderia ser caracterizado como um modo geral de ação, não é algo simples. Os estudantes tanto podem se fixar na situação singular quanto se desviar para aspectos secundários do problema. Em ambos os casos, não chegam à abstração e, por decorrência, à generalização. Portanto, é a consciência do conteúdo central da atividade e das razões de suas ações que leva o aluno a reconhecer nas ações realizadas um modo geral de ação e generalizar o conhecimento, não se restringindo ao modelo da atividade oferecida. Ou seja, não basta que o conteúdo esteja contido na atividade, tampouco basta a ação do aluno: é preciso que este tome consciência da relação da sua ação com o conteúdo da atividade.

Nesse sentido, é necessário que o professor também tenha consciência do conteúdo central da atividade para que, assim, possa prever ações que dirijam a atenção dos estudantes para o objeto da aprendizagem. As interações verbais entre professor e estudantes favorecem o acompanhamento do tipo de relação que o aluno está estabelecendo com o conteúdo: se está preso a situações particulares ou periféricas ou se está voltado para o que é nuclear na atividade proposta.

Em síntese, podemos destacar algumas ações docentes motivadas pelo princípio do caráter consciente da atividade:

a) elaboração de atividades que tenham potencial para promover o modo de ação geral com o conceito;

b) previsão de ações mentais para que o conteúdo central da atividade seja o foco da consciência dos estudantes;

c) atenção para as explicitações verbais dos estudantes, as quais sinalizam se eles estão estabelecendo relação entre o particular e o geral.

\section{Princípio da Unidade entre o Plano Material (ou Materializado) e o Verbal}

A necessidade de criação de situações problema que sejam desencadeadoras da aprendizagem e a necessidade de ascensão do abstrato ao concreto implicam a necessidade de interação entre o plano material 
Interação entre Didática e Teoria Histórico-Cultural

(fenômenos ou objetos), ou representações dele (ilustrações, mapas, filmes, maquetes, etc.), e o plano mental (atuação com as abstrações).

No movimento abstrato/concreto e concreto/abstrato, a mediação da linguagem verbal (oral e escrita) é fundamental, já que pode tornar os processos conscientes, destacar o que é essencial da atividade realizada e focar o(s) conceito(s) nela contidos.

A linguagem (do professor, dos alunos, dos textos científicos) é mediadora entre os dois planos: material e mental é condição para a abstração do conteúdo, para a passagem da ação externa, plano material, para o pensamento teórico. A exposição do professor, o texto científico e as interações verbais entre os estudantes favorecem a transição do ilustrativo para o pensamento conceitual. Ou seja, a linguagem científica/teórica é fundamental para que os estudantes possam abstrair da ação externa material, ilustrativa, os elementos essenciais que a tornaram objeto de aprendizagem.

A leitura de textos científicos pelos estudantes é fundamental para que as sínteses provisórias, resultantes das discussões com o grupo acerca do problema desencadeador de aprendizagem, sejam ampliadas e avancem na direção da compreensão e do uso da linguagem própria da área de conhecimento em pauta.

Em síntese, podemos destacar algumas ações docentes motivadas pelo princípio da unidade entre o plano material (ou materializado) e o verbal:

a) organização de atividades que coloquem em interação o plano material ou materializado (ilustrativo) e a linguagem verbal (oral e escrita);

b) uso de textos científicos e clássicos da respectiva área de conhecimento.

\section{Princípio da Ação Mediada pelo Conceito}

Se os conceitos científicos são mediadores sociais na interação do sujeito com os fenômenos, a apropriação desses mediadores significa a possibilidade de tê-los como instrumento simbólico que orientam as ações mentais (Leontiev, 1978). Nesse sentido, no planejamento de ensino cabe prever a contextualização do conceito, não apenas em termos de sua presença na realidade imediata, mas também em termos de seu movimento lógico-histórico de elaboração.

O lógico reflete não só a história do próprio objeto como também a história do seu conhecimento. Daí a unidade entre o lógico e o histórico ser premissa necessária para a compreensão do processo de movimento do pensamento, da criação da teoria científica. À base do conhecimento dialético do histórico e do lógico resolve-se o problema da correlação entre o pensamento individual e o social; 
em seu desenvolvimento intelectual individual o homem repete em forma resumida toda a história do pensamento humano. A unidade entre o lógico e o histórico é premissa metodológica indispensável na solução de problemas de inter-relação do conhecimento e da estrutura do objeto e conhecimento da história de seu desenvolvimento (Kopnin, 1978, p. 186).

A contextualização não deve ser apresentada aos alunos como uma narrativa histórica, seja por meio de um texto seja por aula expositiva: deve permear as atividades e ser destinada a inserir os estudantes em situações semelhantes àquelas que gestaram a necessidade de elaboração do conceito. Esse tipo de tarefa escolar leva o aluno a compreender os conceitos como instrumentos simbólicos criados pelos homens para atender às suas necessidades de compreensão e intervenção no mundo.

Nos experimentos, durante a elaboração do plano de ensino, antes de definirmos as tarefas de aprendizagem, foi fundamental analisar o conteúdo, de forma a identificar sua essência como instrumento simbólico. Orientamo-nos pela seguinte indagação: esse conceito permite compreender e atuar sobre quais fenômenos? Para tanto, assumimos o pressuposto de que conhecer a origem e o desenvolvimento do conceito na história ajuda-nos identificar sua essência como instrumento da atividade humana, leva-nos a compreender "[...] a que propósito e por que, em que base, com que potencial o objeto veio a existir nessa forma e não em outra" (Pasqualini, 2010, p. 44).

Identificada sua essência, é preciso prever o movimento necessário ao pensamento do estudante para a apreensão do objeto. Nesse momento, precisamos pensar em tarefas de aprendizagem que induzam o aluno a ir se aproximando do conceito.

Para que seja apropriado como instrumento do pensamento, o conceito precisa estar contido nas tarefas de aprendizagem que exijam dos estudantes operações mentais de transição do universal para o particular e vice-versa. Esse não é um percurso natural, espontâneo. Por isso, nas primeiras situações de ensino de um novo conteúdo, como foi exposto anteriormente, as ações precisam ser acompanhadas e orientadas constantemente pelo professor, de modo que, com sua ajuda, o aluno possa fazer o que não poderia fazer sozinho: no caso da aprendizagem conceitual, a transição do universal para o particular e vice-versa. Aos poucos, é preciso incluir outras atividades e novos problemas, de forma a levar o aluno a usar o conceito de forma mais autônoma. Nesse momento, pode-se evidenciar, de forma mais clara, se houve apropriação do conceito.

Atividades que exigem a realização de ações mentais mediadas pelos conceitos (matemáticos, artísticos, filosóficos, físicos, químicos, históricos, etc...) tornam possível, ao estudante, a apropriação do conceito como instrumento simbólico na sua interação com a realidade. 
Interação entre Didática e Teoria Histórico-Cultural

Esse é o fim esperado do ensino de conceitos: a apreensão do concreto pela mediação do abstrato. Portanto, esse ponto de chegada, conforme o caminho a ser organizado e orientado pelo professor constitui, por isso mesmo, o principal aspecto a ser considerado na avaliação da aprendizagem.

Na avaliação não se considera a definição do conceito como sinônimo de sua aprendizagem, o que não significa prescindir dessa definição e sim que é necessário ir além dela. Também não se considera que a repetição de procedimentos adquiridos por meio de treinamentos ou de resolução de listas de exercícios revele aprendizagem. Considera-se que houve aprendizagem quando essa linguagem é internalizada pelo aluno, levando-o a realizar operações mentais com o conceito em novas situações, com novos objetos e diante de novos fenômenos. Dito de outra forma, na avaliação, é preciso verificar se o aluno adquiriu formas de ações gerais ou procedimentos que o tornam capaz de resolver uma categoria de problemas que, para além das diferenças e semelhanças empíricas, são vinculados à mesma base conceitual.

Durante o processo de ensino ou em seu final, é possível encontrar alguns indícios desse tipo de apropriação, de operação mental com o conceito. Tais indícios revelam-se na linguagem do estudante, à medida que ele explica determinados fenômenos; na incorporação da explicação conceitual em suas argumentações; na resolução autônoma de atividades que, embora se diferenciem em seus aspectos externos, em suas manifestações particulares, relacionam-se à mesma base conceitual estudada; na forma como, dependendo do conteúdo, ele age no plano material.

Ao final dos experimentos realizados, após o trabalho sistematicamente orientado pelo professor, com a intenção de captar esses indícios de aprendizagem, levamos os estudantes a analisar novas situações empíricas. Procuramos verificar se eles interagiam com essas situações de um modo teórico, mediado pelos conceitos, ou se as entendiam apenas como um fenômeno particular, novo, sem estabelecer relação com os conceitos estudados. Concluímos que essas atividades de avaliação são ferramentas importantes para verificar se o aluno realiza a ascensão do abstrato ao concreto.

Em síntese, podemos destacar algumas ações docentes motivadas pelo princípio da ação mediada pelo conceito:

a) análise da gênese do conceito no seu aspecto lógico-histórico para buscar o que é nuclear no conceito;

b) elaboração de problemas desencadeadores com a finalidade de levar os alunos a resolvê-los por meio da mediação do conceito;

c) inclusão de novos problemas de aprendizagem ao final do processo de estudo para analisar se os alunos operam mentalmente com o conceito. 


\section{Considerações Finais}

O objetivo do presente texto foi o de apresentar a uma espécie de síntese de princípios didáticos e ações docentes que, submetidos à experimentação em situações de ensino em sala de aula, se mostram favoráveis à aprendizagem. A síntese apresentada ao longo do artigo destaca-se no quadro a seguir:

\begin{tabular}{|c|c|}
\hline PRINCÍPIOS DIDÁTICOS & AÇÕES DOCENTES \\
\hline \multirow{3}{*}{$\begin{array}{l}\text { 1. Princípio do ensino que } \\
\text { desenvolve }\end{array}$} & $\begin{array}{l}\text { a) Avaliação do nível de desenvolvimento atual e previsão } \\
\text { do nível de desenvolvimento esperado }\end{array}$ \\
\hline & $\begin{array}{l}\text { b) Uso de atividades com os conceitos que mobilizam as } \\
\text { Funções Psíquicas Superiores }\end{array}$ \\
\hline & $\begin{array}{l}\text { c) Criação de situações em que os estudantes expressem } \\
\text { verbalmente o que e como estão pensando (como estão } \\
\text { atuando mentalmente com os conceitos) }\end{array}$ \\
\hline \multirow{3}{*}{$\begin{array}{l}\text { 2. Princípio do caráter ativo } \\
\text { da aprendizagem }\end{array}$} & $\begin{array}{l}\text { a) Elaboração de situações problema que permitam inserir } \\
\text { o estudante no horizonte investigativo que deu origem ao } \\
\text { conceito }\end{array}$ \\
\hline & $\begin{array}{l}\text { b) Previsão de momentos em que os alunos dialoguem en- } \\
\text { tre si, elaborem sínteses coletivas, mesmo que provisórias }\end{array}$ \\
\hline & $\begin{array}{l}\text { c) Orientação do processo de elaboração de sínteses con- } \\
\text { ceituais pelos estudantes }\end{array}$ \\
\hline \multirow{3}{*}{$\begin{array}{l}\text { 3. Princípio do caráter } \\
\text { consciente da atividade }\end{array}$} & $\begin{array}{l}\text { a) Elaboração de atividades que tenham potencial para } \\
\text { promover o modo de ação geral com o conceito }\end{array}$ \\
\hline & $\begin{array}{l}\text { b) Previsão de ações mentais para que o conteúdo central } \\
\text { da atividade seja o foco da consciência dos estudantes }\end{array}$ \\
\hline & $\begin{array}{l}\text { c) Atenção para as explicitações verbais dos estudantes, as } \\
\text { quais sinalizam se eles estão estabelecendo relação entre o } \\
\text { particular e o geral }\end{array}$ \\
\hline \multirow{2}{*}{$\begin{array}{l}\text { 4. Princípio da unidade } \\
\text { entre o plano material (ou } \\
\text { materializado) e o verbal: }\end{array}$} & $\begin{array}{l}\text { a) Organização de atividades que coloquem em interação } \\
\text { o plano material ou materializado (ilustrativo) e a lingua- } \\
\text { gem verbal (oral e escrita) }\end{array}$ \\
\hline & $\begin{array}{l}\text { b) Uso de textos científicos e clássicos da respectiva área } \\
\text { de conhecimento }\end{array}$ \\
\hline \multirow{3}{*}{$\begin{array}{l}\text { 5. Princípio da ação } \\
\text { mediada pelo conceito: }\end{array}$} & $\begin{array}{l}\text { a) Análise da gênese do conceito no seu aspecto lógico- } \\
\text {-histórico para buscar o que é nuclear no conceito }\end{array}$ \\
\hline & $\begin{array}{l}\text { b) Elaboração de problemas desencadeadores, cuja solu- } \\
\text { ção exige do aluno a mediação do conceito }\end{array}$ \\
\hline & $\begin{array}{l}\text { c) Inclusão de novos problemas de aprendizagem ao final } \\
\text { do processo de estudo para analisar se os alunos operam } \\
\text { mentalmente com o conceito }\end{array}$ \\
\hline
\end{tabular}


Interação entre Didática e Teoria Histórico-Cultural

Finalizando, destacamos que os princípios formulados e as ações descritas neste texto não são os únicos possíveis; não são definitivos, nem expressam $a$ organização do ensino com base na Teoria Histórico-Cultural: apenas cumprem a função de sinalizar possibilidades para o trabalho docente em aspectos do planejamento, execução e avaliação da atividade de ensino.

Sabemos que uma escola, tal como almejamos, ou seja, aquela que garanta, por meio da aprendizagem do conhecimento sistematizado, a formação do pensamento teórico dos estudantes, não se faz tão somente por meio da adoção de encaminhamos didáticos adequados por parte dos professores, mas temos também a certeza de que sem uma boa didática não se faz uma boa escola.

Recebido em 27 de março de 2014 Aprovado em 21 de outubro de 2014

\section{Notas}

1 Tendo em vista os diversos modos de grafar o nome do estudioso russo Lev Semenovich Vigotski: Vigotsky, Vygotsky, Vygotski, Vigotskii, Vigotski, dentre outras, neste artigo optou-se pelo uso da grafia VIGOTSKI, mas nas referências foi preservada a grafia utilizada em cada edição.

2 O nome desse autor é encontrado com diferentes grafias: Davídov, Davidov e Davydov. No decorrer deste artigo será utilizada a grafia Davidov. Porém, ao se tratar de referência, será mantida a escrita conforme consta na obra referenciada.

3 A fundamentação filosófica e psicológica do experimento formativo apresentada por Zankov pode ser encontrada em Aquino (2013).

4 Freitas (2010) denomina o experimento realizado em sala de aula como parte da investigação didática de experimento didático formativo.

5 Tais experimentos, bem como os dados de campo que deles resultaram fizeram parte das pesquisas de Mestrado realizadas sob nossa orientação no Programa de Pós-Graduação em Educação da Universidade Estadual de Maringá por Rodrigues (2006), Cavaleiro (2009), Belieri (2012) e Oliveira (2013).

6 “A expressão 'ensino desenvolvimental' é a tradução de developmental teaching, expresssão que aparece na tradução do russo para o inglês do livro de Davydov publicado na Rússia em 1996, Problems of developmental teaching. Corresponde, também, à tradução de enseñanza desarrollante, como aparece na tradução do russo para o espanhol, feita por Marta Shuare" (Libâneo; Freitas, 2013, p. 316).

\section{Referências}

AMARAL, Ana Lúcia. As Eternas Encruzilhadas: de como selecionar caminhos para a formação do professor de ensino superior. In: ROMANOWSKI, Joana Paulin; MARTINS, Pura Lúcia Oliver; JUNQUEIRA, Sérgio R. A. Conhecimento Local e Conhecimento Universal: pesquisa. Didática e ação docente. Curitiba: Champagnat, 2004. P. 139-150.

394 Educação \& Realidade, Porto Alegre, v. 40, n. 2, p. 375-397, abr./jun. 2015. 
ANDRÉ, Marli. Tendências da Pesquisa e do Conhecimento Didático no Início dos Anos 2000. In: ENCONTRO NACIONAL DE DIDÁTICA E PRÁTICAS DE ENSINO (ENDIPE), 14., 2008, Porto Alegre. Anais... Porto Alegre, 2008. P. 487-499.

AQUINO, Orlando Fernández. L. V. Zankov: aproximações à sua vida e obra. In: LONGAREZI, Andréa Maturano; PUENTES, Roberto Valdés (Org.). Ensino Desenvolvimental: vida, pensamento e obra dos principais representantes russos. Uberlândia: EDUFU, 2013. P. 233-261.

BELIERI, Cleder Mariano. Aprendizagem de Conceitos Filosóficos no Ensino Médio. 2012. 162 f. Dissertação (Mestrado em Educação) - Programa de Pós- Graduação em Educação, Universidade Estadual de Maringá, Maringá, 2012.

BERNARDES, Maria Eliza Mattosinho. Mediações Simbólicas na Atividade Pedagógica: contribuições da Teoria Histórico-Cultural para o ensino e a aprendizagem. Curitiba: CRV, 2012.

BOGOYAVLENSKY, D. N.; MENCHINSKAYA, N. A Psicologia da Aprendizagem de 1900 a 1960. In: LURIA, Alexander Romanovich et al. Psicologia e Pedagogia I: bases psicológicas da aprendizagem e do desenvolvimento. Lisboa: Estampa, 1977. P. 145-226.

CAVALEIRO, Patrícia Cristina Formaggi. Organização do Ensino da Linguagem Escrita: contribuições da Abordagem Histórico-Cultural. 2009. 183 f. Dissertação (Mestrado em Educação) - Programa de Pós-Graduação em Educação, Universidade Estadual de Maringá, Maringá, 2009.

DAVÍDOV, Vasili. Análisis de los Principios Didácticos de la Escuela Tradicional y Posibles Principios de Enseñanza en el Futuro Proximo. In: DAVÍDOV, Vasili; SHUARE, Marta. La Psicología Evolutiva y Pedagógica em la URSS: antología. Moscú: Editorial Progreso, 1987. P. 143-154.

DAVIDOV, Vasili. La Enseñanza Escolar y el Desarrollo Psíquico. Moscú: Editorial Progreso, 1988.

DAVIDOV, Vasili; MÁRKOVA, Aelita. La Concepción de la Actividad de Estudio de los Escolares. In: DAVIDOV, Vasili; SHUARE, Marta. La Psicología Evolutiva y Pedagógica em la URSS: antología. Moscú: Editorial Progreso, 1987. P. 173-193.

DAVYDOV, Vasili. Tipos de Generalización en la Enseñanza. Habana: Pueblo Y Educación, 1982.

DAVYDOV, Vasili. Problems of Developmental Teaching: the experience of theoretical and experimental psychological research. Soviet Education, New York, v. XXX, n. 8, 1988.

FREITAS, Raquel Aparecida Marra da Madeira. Pesquisa em Didática: o experimento didático formativo. In: ENCONTRO DE PESQUISA EM EDUCAÇÃO DA ANPED CENTRO-OESTE: DESAFIOS DA PRODUÇÃO E DIVULGAÇÃO DO CONHECIMENTO, 10., 2010, Uberlândia. Anais... Uberlândia, 2010. P. 1-11.

HEDEGAARD, Marianne. A Zona de Desenvolvimento Proximal como Base para o Ensino. In: DANIEL, Harry (Org.). Uma Introdução a Vygotski. São Paulo: Loyola, 2002. P. 199-227.

KOPNIN, Pável Vassílievitch. A Dialética como Lógica e Teoria do Conhecimento. Rio de Janeiro: Civilização Brasileira, 1978.

LEONTIEV, Alexei Nikolaievich. O Desenvolvimento do Psiquismo. Lisboa: Livros Horizontes, 1978.

LEONTIEV, Alexei Nikolaievich. Actividad, CONCIENCIA, Personalidad. Habana: Pueblo y Educación, 1983.

Educação \& Realidade, Porto Alegre, v. 40, n. 2, p. 375-397, abr./jun. 2015. 
Interação entre Didática e Teoria Histórico-Cultural

LIBÂNEO, José Carlos. O Campo Teórico e Profissional da Didática Hoje: entre Ítaca e o canto das sereias. In: EGGERT, Edla et al. Trajetórias e Processos de Ensinar e Aprender: didática e formação de professores. Porto Alegre: EDIPUCRS, 2008. P. 234-252.

LIBÂNEO, José Carlos; FREITAS, Raquel Aparecida Marra da Madeira. Vasily Vasilyevich Davydov: a escola e a formação do pensamento teórico-científico. In: LONGAREZI, Andréa Maturano; PUENTES, Roberto Valdés (Org.). Ensino Desenvolvimental: vida, pensamento e obra dos principais representantes russos. Uberlândia: EDUFU, 2013. P. 315-350.

MARCONDES, Maria Inês; LEITE, Miriam Soares; LEITE, Vania Finholdt. A Pesquisa Contemporânea em Didática: contribuições para a prática pedagógica. Educação em Revista, Belo Horizonte, v. 27, n. 03, p. 305-334, 2011.

MORAES, Maria Célia Marcondes de; TORRIGLIA, Patrícia Laura. Sentido do ser Docente e da Construção de seu Conhecimento. In: MORAES, Maria Célia Marcondes de (Org.). Iluminismo às Avessas. Rio de Janeiro: DP\&A, 2003. P. 45-60.

MOURA, Manoel Oriosvaldo. A Atividade de Ensino como Unidade Formadora. Bolema, São Paulo, ano II, n. 12, p. 29-43, 1996.

MOURA, Manoel Oriosvaldo. A Atividade de Ensino como Ação Formadora. In: CASTRO, Amélia Domingues de; CARVALHO, Anna Maria Pessoa de (Org.) Ensinar a Ensinar: didática para a escola. São Paulo: Editora Pioneira, 2001. P. 143-162.

MOURA, Manoel Oriosvaldo (Org.). A Atividade Pedagógica na Teoria Histórico-Cultural. Brasília: Liber Livro, 2010.

NASCIMENTO, Carolina Picchetti. A Organização do Ensino e a Formação do Pensamento Estético-Artísticona Teoria Histórico-Cultural. 2010. 249 f. Dissertação (Mestrado em Educação) - Faculdade de Educação, Universidade de São Paulo, São Paulo, 2010.

NÚÑEZ, Isauro Beltrán. Vygotsky, Leontiev, Galperin: formação de conceitos e princípiosdidáticos. Brasília: Liber Livro, 2009.

OLIVEIRA, Maria Rita Neto Sales. Desafios na Área da Didática. In: ANDRÉ, Marli Eliza Dalmazo Afonso de; OLIVEIRA, Maria Rita Neto Sales. Alternativas para o Ensino de Didática. Campinas: Papirus, 2011. P. 129-143.

OLIVEIRA, Valdiléia Xavier de. “Olha, é só um truque, tem desenho lá!” - o Ensino de Arte com Base em Pressupostos da Teoria Histórico-Cultural. 2013. 213 f. Dissertação (Mestrado em Educação) - Programa de Pós-Graduação em Educação, Universidade Estadual de Maringá, Maringá, 2013.

PASQUALINI, Juliana C. Princípios para a Organização do Ensino na Educação Infantil na Perspectiva Histórico-Cultural: um estudo a partir da análise da prática do professor. 2010. 268 f. Tese (Doutorado em Educação) - Programa de Pós-Graduação em Educação, Universidade Estadual Paulista, Araraquara, 2010.

PIMENTA, Selma Garrido. Epistemologia da Prática Ressignificando a Didática. In: ENCONTRO NACIONAL DE DIDÁTICA E PRÁTICAS DE ENSINO (ENDIPE), 14., 2008, Porto Alegre. Anais... Porto Alegre, 2008. P. 602-625.

RODRIGUES, Vera Lúcia Gouvêa de Camargo. Aprendizagem do Conceito de Volume e o Desenvolvimento Intelectual: uma experiência no ensino fundamental. 2006. 167 f. Dissertação (Mestrado em Educação) - Programa de Pós-Graduação em Educação, Universidade Estadual de Maringá, Maringá, 2006.

396 Educação \& Realidade, Porto Alegre, v. 40, n. 2, p. 375-397, abr./jun. 2015. 
SFORNI, Marta Sueli de Faria. Escolarização, Didática e Inserção Social: algumas reflexões. In: SOMMER, Luís Henrique; QUARTIERO, Elisa Maria (Org.). Pesquisa, Educação e Inserção Social: olhares da região sul. Canoas: Editora ULBRA, 2008. V. 1. P. 381-390.

SFORNI, Marta Sueli de Faria. Perspectivas de Formação, Definição de Objetivos, Conteúdos e Metodologia de Ensino: aportes da abordagem histórico-cultural. In: PARANÁ, Secretaria de Estado da Educação. Organização do Trabalho Pedagógico. Curitiba: SEED, 2010. P. 97-109. Disponível em: <http://www.educadores.diaadia.pr.gov.br/arquivos/File/cadernos_tematicos/caderno_tematico_otp.pdf >. Acesso em: 28 jul. 2013.

SFORNI, Marta Sueli de Faria. A Produção Científica Brasileira sobre a Organização do Ensino Fundamentada na Teoria Histórico-Cultural. In: JORNADA DO HISTEDBR, 11., 2013, Cascavel. Anais... Cascavel, 2013. P. 01-16.

VYGOTSKI, Liev Semiónovich. Obras Escogidas: tomo II. Madri: Visor, 1993.

VYGOTSKY, Liev Semiónovich. Aprendizagem e Desenvolvimento Intelectual na Idade Escolar. In: VYGOTSKY, Liev Seminiónovich; LURIA, Alexander Romanovich; LEONTIEV, Alexei Nikolaievich. Linguagem, Desenvolvimento e Aprendizagem. São Paulo: Ícone, Editora da Universidade de São Paulo, 1998. P. 103-117.

Marta Sueli de Faria Sforni é doutora em Educação pela USP, professora do Departamento de Teoria e Prática da Educação e do Programa de Pós- Graduação em Educação da Universidade Estadual de Maringá. Líder do Grupo de Estudos e Pesquisas Ensino, Aprendizagem e Conteúdo Escolar. E-mail: martasforni@uol.com.br 